\title{
Steroid-sensitive Mechanism of Soluble Immune Response Suppressor Production in Steroid-responsive Nephrotic Syndrome
}

\author{
H. William Schnaper and Thomas M. Aune \\ With the technical assistance of Rhonda K. Roby \\ Department of Pathology and Laboratory Medicine, The Jewish Hospital of St. Louis, and the Departments \\ of Pediatrics and Pathology, Washington University School of Medicine, St. Louis, Missouri 63110
}

\begin{abstract}
Soluble immune response suppressor (SIRS), a lymphokine that suppresses antibody production and delayed type hypersensitivity in vivo, has been detected in urine and serum from certain patients with nephrotic syndrome. In the present paper, the relationship between SIRS production and nephrotic syndrome is further characterized. A striking correlation was found between detection of SIRS and the presence of steroid-responsive nephrotic syndrome (SRNS). A potential mechanism of SIRS production in SRNS patients was identified, in that $(a)$ lymphocytes from patients produced SIRS without requiring activation by exogenous agents, and (b) incubation of normal lymphocytes with serum from patients activated the cells to secrete SIRS in culture. Although SIRS disappears rapidly from urine or serum after initiation of corticosteroid therapy, hydrocortisone $\left(10^{-6}-10^{-7} \mathrm{M}\right)$ did not block secretion of SIRS by activated suppressor cells. It did, however, inhibit in vitro activation of lymphocytes to produce SIRS by concanavalin A, interferon, or SRNS patient serum. The association of suppressor cell activation with SRNS and the sensitivity of both to steroids suggest that the pathogeneses of albuminuria and SIRS production are related.
\end{abstract}

\section{Introduction}

Patients with nephrotic syndrome frequently manifest suppressed clinical and experimental immune responsiveness. We have previously reported identification of the lymphokine, soluble immune response suppressor (SIRS) ${ }^{1}$ in urine and serum of children with minimal change nephrotic syndrome (MCNS) and other forms of nephrotic syndrome classically associated with an immune pathogenesis (1). This protein, which is produced by concanavalin A (Con A) or interferon (IFN)-activated suppressor $\mathrm{T}$ lymphocytes in vitro, has been purified to homogeneity

Address reprint requests to Dr. Schnaper. Presented in part at the Annual Meeting of the Society for Pediatric Research in Washington, DC, May 1985 (Pediatr. Res. 19:382A) and the Annual Meeting of the American Society of Nephrology in New Orleans, December 1985 (1986. Kidney Int. 29:290A).

Received for publication 14 February 1986 and in revised form 25 August 1986.

1. Abbreviations used in this paper: Con A, concanavalin A; IFN, interferon; MCNS, minimal change nephrotic syndrome; PBMC, peripheral blood mononuclear cells; SIRS, soluble immune response suppressor; SRNS, steroid responsive nephrotic syndrome.

J. Clin. Invest.

(c) The American Society for Clinical Investigation, Inc.

0021-9738/87/01/0257/08 \$1.00

Volume 79, January 1987, 257-264 and has a molecular weight of 15,000 D. It inhibits antibody production and tumor cell division in vitro (2). Recent data indicate that SIRS also suppresses in vivo antibody production and delayed type hypersensitivity in mice (3), suggesting that SIRS activity may account for the immune suppression observed in some nephrotic patients. In our previous report SIRS activity was not found in patients who were nephrotic because of focal segmental glomerulosclerosis or congenital nephrotic syndrome, or in nonnephrotic patients with acute glomerulonephritis. Further, SIRS disappeared from urine of children with MCNS soon after initiation of corticosteroid therapy but before entry of the patient into remission. In patients with nephrosis resulting from glomerulonephritis who experienced normalization of serum albumin concentration after steroid therapy, SIRS excretion ceased despite continued signs of renal inflammation such as hypocomplementemia and abnormal urinary sediment. Production of SIRS thus was associated with certain causes of nephrotic syndrome and appeared to be inhibited by steroid therapy (1).

These data raise questions concerning the source of SIRS in nephrotic patients, the factors that determine the presence of SIRS production in certain cases, and the relationship between the efficacy of steroid therapy for nephrosis and the disappearance of SIRS from patient urine. Results presented here show that lymphocytes are at least one source of SIRS in patients with steroid-responsive nephrotic syndrome (SRNS) and that hydrocortisone inhibits activation of lymphocytes to produce SIRS by Con A, IFNs or a serum factor also present in patients with SRNS. All patients tested who responded to steroid therapy showed urine or serum SIRS activity. The striking correlation between SRNS and SIRS production, and the sensitivity of both albuminuria and SIRS production to steroids, suggest a relationship between SIRS production and the pathogenesis of SRNS.

\section{Methods}

Unless otherwise specified all chemicals were reagent grade and purchased from commercial sources.

Patient population. Patients studied in these experiments were observed by the Renal Divisions of St. Louis Children's Hospital, Barnes Hospital, or the Jewish Hospital of St. Louis, Washington University School of Medicine. Diagnosis was established by renal biopsy except in some children aged 2-7 yr. These patients met certain clinical and laboratory criteria, including cessation of proteinuria with steroid therapy, which indicate a presumptive diagnosis of MCNS (4). Any nephrotic patient, regardless of histopathology on renal biopsy, was classified as having SRNS if diuresis occurred and serum albumin became normal with steroid therapy. In some cases of nephrosis, such as in patients with membranoproliferative glomerulonephritis, serologic findings, or urinalysis indicated persistence of active nephritis despite normalization of serum albumin levels $(>3.2 \mathrm{~g} / \mathrm{dl})$ after treatment. Although the nephritis did not resolve with therapy, these patients were considered to have SRNS because the nephrotic syndrome resolved with treatment. 
Collection and treatment of test samples. All specimens were obtained from patients or healthy volunteers under protocols approved by the Washington University School of Medicine and Jewish Hospital of St. Louis Human Studies Committees. Urine was obtained, processed and lyophilized as described previously (1). Serum was obtained from patients during venipuncture for other, routine laboratory tests. After centrifugation of whole clotted blood, serum was removed, filter sterilized, and stored at $-20^{\circ} \mathrm{C}$ until testing for SIRS activity.

In vitro activation of lymphocytes to produce SIRS. Peripheral blood mononuclear cells (PBMC) were obtained from patients and healthy volunteers by venipuncture and withdrawal of heparinized whole blood. The sample was diluted 1:1 with Hanks' balanced salt solution and centrifuged through a Ficoll/sodium diatrizoate gradient according to the method of Boyum (5). After washing, $3 \times 10^{6} \mathrm{PBMC}$ were suspended in $1.5 \mathrm{ml}$ RPMI 1640 medium supplemented with penicillin/streptomycin, glutamine, nonessential amino acids, and $10 \%$ fetal calf serum (lot 58101, Reheis Chemical Co.,). Con A or IFN was added to cultures, which were then incubated in sterile, $12-\mathrm{ml}$, round-bottom, plastic culture tubes for $24 \mathrm{~h}$ in $5 \%$ humidified $\mathrm{CO}_{2}$ in air at $37^{\circ} \mathrm{C}$. The cells were washed twice with Hanks' solution and resuspended in fresh culture medium for an additional $24 \mathrm{~h}$. After centrifugation to remove the PBMC, culture supernatant was aspirated by pasteur pipette. Supernatant fluids of PBMC cultures prepared in this manner contain SIRS, as demonstrated by several functional and physical criteria $(1,6)$.

Assay for SIRS activity. Human splenocytes were obtained aseptically from cadaver kidney transplant donors at the time of organ harvest, processed as described previously (6), and preserved frozen in liquid nitrogen until use (1). Urine, serum, or lymphocyte supernatant was added to $2 \times 10^{6}$ human splenocytes cultured in $1 \mathrm{ml}$ supplemented RPMI 1640 medium with $5 \mu \mathrm{g}$ pokeweed mitogen for $6 \mathrm{~d}$ in humidified $5 \% \mathrm{CO}_{2}$ in air. These cultures were assayed for polyclonal IgM production by a slide modification of the Jerne hemolytic plaque-forming cell (PFC) assay (7) as described previously (8); PBMC cultures may be similarly assayed for PFC response in these types of experiments. Fluids that caused $>50 \%$ suppression of PFC response compared with the response of control cultures were considered to show significant suppressive activity. Suppression was confirmed to be SIRS-mediated by the ability of monoclonal anti-SIRS antibody coupled to Sepharose 4B (Sigma Chemical Co., St. Louis, MO) to absorb suppressive activity from solution (9).

Separation of T cell subpopulations. Monoclonal antibodies to human helper/inducer cell (OKT4) and suppressor/cytotoxic cell (OKT8) surface antigens were used to isolate these two populations as described previously (6). Briefly, $2 \times 10^{7}$ PBMC in $2 \mathrm{ml}$ RPMI 1640 medium were incubated with $10 \mu \mathrm{l}$ monoclonal antibody reconstituted according to the package insert (Ortho-mune, Ortho Diagnostic Systems, Raritan, NJ) at $4^{\circ} \mathrm{C}$ for $45 \mathrm{~min}$, washed, and resuspended in rabbit complement at $37^{\circ} \mathrm{C}$ for 45 min. Alternatively, antibody-treated cells were layered onto $100 \times 15$ mm sterile plastic culture dishes (Fisher Scientific Co., Pittsburgh, PA) coated with goat anti-mouse IgG $(0.75 \mu \mathrm{g} / \mathrm{ml})$. Nonadherent cells were obtained after the plates were gently swirled, and adherent cells were then removed by vigorous pipetting. After treatment, cells were washed and resuspended at $2 \times 10^{6} \mathrm{cells} / \mathrm{ml}$ in culture medium.

\section{Results}

Serum SIRS activity in nephrotic syndrome. We previously reported that four children with urinary excretion of SIRS also had SIRS activity in their serum (1). Further investigation has confirmed that virtually every adult and pediatric patient with SIRS activity had SIRS in both urine and serum. In the single exception, SIRS was present in serum obtained before initiation of steroid therapy, but no urine was obtained for $24 \mathrm{~h}$ after initiation of treatment; SIRS activity was not found in a subsequent urine specimen. Fig. 1 shows the suppressive effect of patient serum added to PFC cultures. While control serum did not suppress responses, suppression was caused by addition of

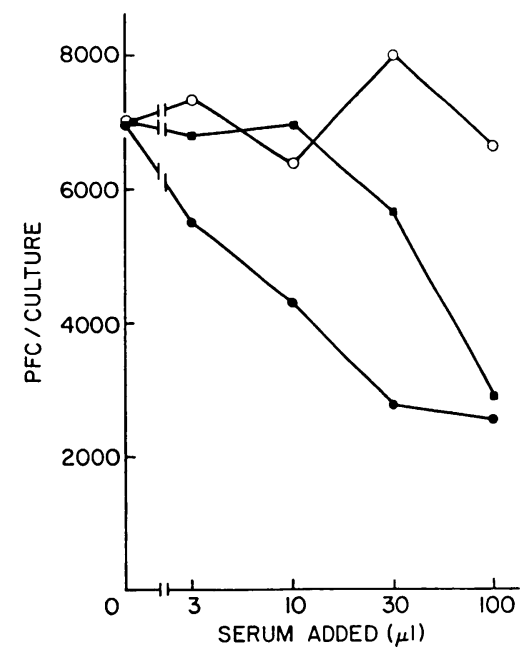

Figure 1. Suppression of splenocyte PFC responses by serum from a patient with SRNS. Varying amounts of control serum (open circle), serum from a patient with MCNS (closed circle), or MCNS serum incubated for $1 \mathrm{~h}$ with monoclonal antimurine SIRS antibody coupled to Sepharose (closed box) were added to 2 $\times 10^{6}$ spleen cells in supplemented RPMI 1640 medium stimulated with pokeweed mitogen, at the time of the

culture initiation. After $6 \mathrm{~d}$, cells were assayed for polyclonal IgM production by a slide modification of the Jerne hemolytic plaque-forming cell assay.

$\sim 10 \mu \mathrm{l}$ (1\% culture volume) of patient serum. Absorption of the serum with monoclonal anti-SIRS antibody significantly decreased suppression, but addition of much larger amounts of antibody-absorbed serum did suppress responses. The ability of increased doses of antibody-absorbed serum to suppress responses, which was consistently observed in experiments with sera from seven patients, could result from incomplete absorption of the factor from serum or from the presence of an additional suppressive moiety such as low density lipoprotein (10), which has inhibitory effects on in vitro immune responses.

Disappearance of SIRS activity from serum with treatment. SIRS disappears from urine shortly after initiation of steroid therapy. To determine whether SIRS also disappears from serum during treatment, sera were obtained in a serial fashion during the treatment course from four patients in relapse. In each case, assay for SIRS activity showed results similar to those for the patient with MCNS described in Table I. SIRS was present before therapy, but not thereafter. The patient entered remission on day 8. These results show that, as with urine SIRS, serum SIRS

Table I. Effect of Corticosteroid Therapy on Suppressive Activity of Serum from a Patient with MCNS*

\begin{tabular}{cc}
\hline Day of treatment & PFC/culture \\
\hline Control response & 1,400 \\
Day 0 & 380 \\
Day 1 & 1,400 \\
Day 3 & 1,920 \\
Day 4 & 1,960
\end{tabular}

\footnotetext{
* Samples were obtained from a patient with MCNS before initiation of steroid therapy (prednisone, $2 \mathrm{mg} / \mathrm{kg}$ per d orally) and on various days subsequently. Serum was filter sterilized and $30 \mu \mathrm{l}$ from each sample was added to 1-ml cultures of pokeweed mitogen-stimulated lymphocytes, which were assayed $6 \mathrm{~d}$ later for polyclonal IgM production by plaque-forming cell (PFC) assay. Suppression from the day 0 sample was confirmed as SIRS-mediated by antibody absorption. Similar results were obtained with sera from three other patients.
} 
activity disappears soon after initiation of steroid therapy but before entry of the patient into remission.

Correlation of SIRS activity with steroid responsiveness. A total of 39 patients with nephrotic syndrome has been tested for urine and/or serum SIRS activity. These include adult as well as pediatric patients. Table II shows the number of patients with each histopathologic diagnosis who were tested, with the data broken down according to whether patients had SRNS or were steroid unresponsive. Untreated patients with nephrosis secondary to a variety of histopathologic diagnoses produced SIRS, but some patients with the same diagnoses did not produce SIRS. The striking finding is the absolute correlation of SIRS production with steroid responsiveness, regardless of diagnosis or age of the patient. All patients who had SRNS produced SIRS, while SIRS was not detected in those who remained nephrotic despite steroid treatment. Nonnephrotic patients with acute glomerulonephritis or other causes for proteinuria had no SIRS activity (1, and unpublished observation). SIRS production was a valid predictor of response; in six patients, detection of SIRS activity before clinical response suggested the eventual efficacy of corticosteroid therapy. In contrast, three patients followed prospectively who did not produce SIRS proved to be steroid unresponsive. One of these was a 2-yr-old girl with clinical features typical of MCNS. On subsequent biopsy she was found to have immune complex glomerulonephritis.

Production of SIRS by PBMC from patients with SRNS. SIRS was first demonstrated in cultures containing suppressor $T$ lymphocytes activated by Con A or IFN $(6,11,12)$. To determine whether activated, circulating lymphocytes were a source

Table II. SIRS Production by Nephrotic Patients*

\begin{tabular}{lll}
\hline & \multicolumn{2}{l}{$\begin{array}{l}\text { Nephrotic subjects with SIRS } \\
\text { production }\end{array}$} \\
\cline { 2 - 3 } $\begin{array}{l}\text { Histopathologic } \\
\text { diagnosis }\end{array}$ & $\begin{array}{l}\text { Steroid } \\
\text { responsive }\end{array}$ & $\begin{array}{l}\text { Steroid } \\
\text { unresponsive }\end{array}$ \\
\hline $\begin{array}{l}\text { Minimal change } \\
\text { nephrotic syndrome }\end{array}$ & $20 / 20^{\ddagger}$ & $0 / 2$ \\
$\begin{array}{l}\text { Focal segmental } \\
\text { glomerulosclerosis }\end{array}$ & $1 / 1$ & $0 / 3$ \\
$\begin{array}{l}\text { Membranoproliferative } \\
\text { glomerulonephritis }\end{array}$ & $3 / 3$ & $0 / 0$ \\
$\begin{array}{l}\text { Membranous } \\
\text { nephropathy }\end{array}$ & $2 / 2$ & $0 / 0$ \\
$\begin{array}{l}\text { Immune complex disease } \\
\text { Other }\end{array}$ & $2 / 2$ & $0 / 2$ \\
Total & $1 / 1$ & $0 / 3$ \\
\hline
\end{tabular}

* Patients were assayed for urine and/or serum SIRS activity as determined by suppression of polyclonal plaque-forming cell response of pokeweed mitogen-stimulated splenocytes. Suppressive activity was confirmed as SIRS-mediated by absorption with anti-SIRS antibodies in all patients except five with MCNS. Data from 13 patients with SRNS and 4 steroid-unresponsive patients were previously reported in reference 1 .

‡ Numerator and denominator represent number of patients with SIRS activity compared to numbers of patients tested.

${ }^{8}$ Steroid-responsive patient had Henoch-Schoenlein purpura. Unresponsive patients included one each with congenital nephrotic syndrome, diabetic nephropathy, and amyloidosis.

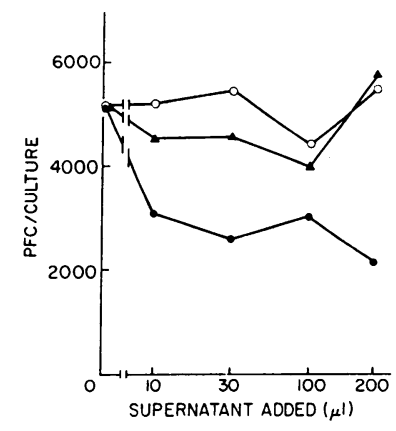

Figure 2. Suppressive effect of supernatant fluid from cultures of SRNS patient PMBC. Cells obtained by venipuncture and isolated by centrifugation through a Ficoll-sodium diatrizoate gradient were cultured for $24 \mathrm{~h}$. Supernatant of PBMC from a normal donor (open circle) or from a patient with MCNS (closed circle), or patient PMBC supernatant absorbed with anti-SIRS antibody (closed triangle), was tested for suppressive effect on PFC responses of pokeweed mitogen-stimulated splenocyte cultures.

of systemic SIRS activity in patients with SRNS, $3 \times 10^{6} \mathrm{PBMC}$ were cultured in $1.5 \mathrm{ml}$ medium without Con A or IFN for 24 $h$ and the supernatant tested for SIRS. Fig. 2 shows the results of one such experiment, in which supernatant of PBMC from a patient with MCNS, but not a healthy volunteer, suppressed PFC responses. Absorption of the fluid with anti-SIRS antibody coupled to Sepharose abolished suppressive activity, confirming that suppression was mediated by SIRS. Further, suppression by this and other SRNS patient cell supernatants required that it be added near the time of initiation of PFC cultures or that it be activated with $\mathrm{H}_{2} \mathrm{O}_{2}$ (Table III). These data are characteristic for SIRS produced by suppressor cells activated in vitro and show that SIRS secreted by SRNS patient PBMC is both antigenically and functionally similar to conventional human SIRS (6) and to SIRS found in patient urine (1).

Secretion of SIRS by patient lymphocytes was not significantly enhanced by treatment of the cells with Con A. Incubation of patient PBMC cultures for $48 \mathrm{~h}$ rather than $24 \mathrm{~h}$ did not yield increased SIRS activity in the supernatant, and no significant activity was found in supernatant of untreated patient PBMC which were washed after $24 \mathrm{~h}$ and cultured for another $24 \mathrm{~h}$. These findings show that the maximum duration of SIRS production by cultured patient cells was $24 \mathrm{~h}$. Further, the amount of SIRS activity secreted by patient lymphocytes approximated that obtained from normal control lymphocytes incubated with Con A, $30 \mu \mathrm{g} / \mathrm{ml}$. These findings show that PBMC from patients with SRNS secrete SIRS in culture without requiring activation by an exogenous agent, suggesting that the PBMC were activated in vivo to produce SIRS. Production of SIRS by patient lym-

Table III. Kinetics of Suppression of PFC Responses by Supernatant of PBMC from a Patient with SRNS*

\begin{tabular}{lll}
\hline Factor added & Day added & PFC/culture \\
\hline None & - & 6,670 \\
Supernatant & 0 & 3,320 \\
Supernatant & 5 & 5,800 \\
Supernatant $+\mathrm{H}_{2} \mathrm{O}_{2}{ }^{*}$ & 5 & 3,480 \\
\hline
\end{tabular}

* PBMC $\left(3 \times 10^{6}\right)$ were cultured in $1.5 \mathrm{ml}$ media for $24 \mathrm{~h}$ and the supernatant was harvested; $100 \mu \mathrm{l}$ was added to $6-\mathrm{d}$ splenocyte cultures on the day of culture initiation or $5 \mathrm{~d}$ later.

$\ddagger$ Reacted with $\mathrm{H}_{2} \mathrm{O}_{2}$ at a final concentration of $10^{-6} \mathrm{M}$ for $20 \mathrm{~min}$ before adding to culture. This is the protocol used to activate SIRS to SIRS $_{\mathrm{ox}}$. Peroxide-treated medium had no effect on culture responses. 
phocytes appeared to be similar to that resulting from in vitro activation of normal PBMC by Con A or IFN.

Lymphocytes from six patients with SRNS have been tested for SIRS secretion (Table IV). PBMC from all patients were found to secrete SIRS spontaneously. In contrast, PBMC from six healthy volunteers did not secrete SIRS. Further, PBMC from three patients with steroid-unresponsive nephrosis did not secrete SIRS. All subjects in the control and steroid-unresponsive groups showed normal SIRS production when PBMC were stimulated with Con A. While the number of patients evaluated is small, the data indicate that serum SIRS activity in patients with SRNS is associated with the presence of circulating lymphocytes activated to secrete SIRS, and suggest that this lymphocyte activity is a source of serum SIRS.

Activation of normal lymphocytes to produce SIRS by SRNS patient serum. These data suggested that suppressor cells were activated in vivo to produce SIRS. The observation in previous experiments that SRNS patient serum continued to have some suppressive activity after absorption with anti-SIRS antibody (Fig. 1) raised the possibility that an agent in patient serum that was antigenically distinct from SIRS could activate lymphocytes to produce SIRS. To test this hypothesis, PBMC obtained from normal donors were incubated for $24 \mathrm{~h}$ with patient serum, washed, and cultured for an additional $24 \mathrm{~h}$. The culture supernatants were then tested for SIRS activity. Fig. 3 shows the results of one experiment. Serum from a normal donor did not induce significant suppressive activity. However, PBMC incu-

Table IV. Assay of PBMC Supernatant for SIRS Activity*

\begin{tabular}{|c|c|c|c|}
\hline \multirow[b]{2}{*}{ Subject } & \multirow[b]{2}{*}{ Maximum suppression } & \multicolumn{2}{|c|}{ SIRS activity } \\
\hline & & Untreated & $\begin{array}{l}\text { Antibody } \\
\text { absorbed }\end{array}$ \\
\hline & $\%$ & $U / m l$ & $U / m l$ \\
\hline \multicolumn{4}{|c|}{ SRNS patients } \\
\hline 1 & 71 & 100 & 0 \\
\hline 2 & 60 & 33 & 0 \\
\hline 3 & 59 & 27 & 0 \\
\hline 4 & 78 & 100 & $\mathrm{ND}^{\ddagger}$ \\
\hline 5 & 60 & 125 & 0 \\
\hline 6 & 81 & 133 & 0 \\
\hline \multicolumn{4}{|c|}{$\begin{array}{l}\text { Steroid-unresponsive } \\
\text { nephrotic patients }\end{array}$} \\
\hline 7 & 15 & 0 & 0 \\
\hline 8 & 5 & 0 & 0 \\
\hline 9 & 0 & 0 & 0 \\
\hline \multicolumn{4}{|c|}{ Normal subjects } \\
\hline A & 0 & 0 & ND \\
\hline B & 0 & 0 & ND \\
\hline $\mathrm{C}$ & 20 & 0 & ND \\
\hline D & 0 & 0 & ND \\
\hline $\mathrm{E}$ & 10 & 0 & ND \\
\hline $\mathbf{F}$ & 0 & 0 & ND \\
\hline
\end{tabular}

* PBMC were obtained from nephrotic donors with SRNS or steroid unresponsive disease, or from healthy volunteers, by centrifugation over Ficoll-sodium diatrizoate. The cells were cultured for $24 \mathrm{~h}$ in supplemented RPMI 1640 medium which was then tested for suppressive activity.

${ }^{\ddagger} \mathrm{ND}$, not determined.

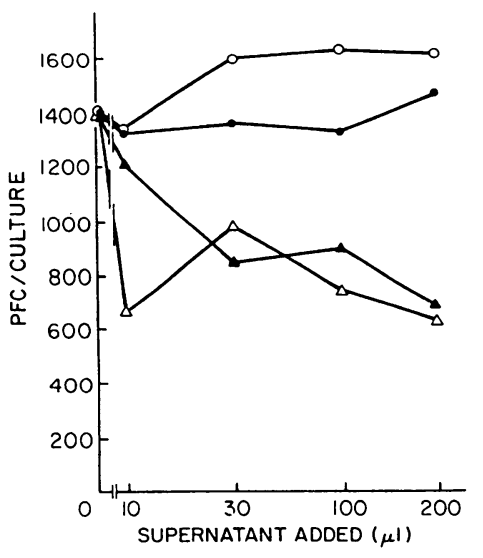

Figure 3. Activation of SIRS-producing lymphocytes by serum from a patient with SRNS. PBMC from a normal donor were incubated with medium alone (closed circle), $7 \%$ serum from a healthy donor (open circle), or $2 \%$ (closed triangle) or 7 percent (open triangle) serum from a patient with MCNS, for $24 \mathrm{~h}$. The cells were washed and cultured for an additional $24 \mathrm{~h}$, and the culture supernatant tested for suppressive activity on PFC responses. Suppression was confirmed as SIRS-mediated by absorption with anti-SIRS antibody.

bated with serum from a patient with MCNS released suppressive activity into the culture medium. Suppression was confirmed as SIRS-mediated by absorption with anti-SIRS antibodies.

Activity in supernatants of cells incubated with SRNS patient serum did not result from carryover of SIRS into the supernatant by serum-treated lymphocytes. Table $\mathrm{V}$ shows that absorption of serum with anti-SIRS antibody significantly reduced the amount of suppressive activity in patient sera but did not affect activation of cells to secrete SIRS. The SIRS-inducing factor is thus antigenically distinct from SIRS. Similar results were obtained in two other experiments. Sera from six patients with SRNS have been tested for ability to induce SIRS production, including one each with membranous nephropathy and membranoproliferative glomerulonephritis, and one adult and three children with MCNS. All six sera activated normal PBMC to produce SIRS. Serum from patients with steroid unresponsive nephrotic syndrome did not activate PBMC to produce SIRS. This SIRS-inducing activity may account for in vivo activation of lymphocytes to produce SIRS in SRNS.

Table V. Effect of Absorption with Anti-SIRS Antibody on SIRS and SIRS-inducing Activity of Patient Serum

\begin{tabular}{lcc}
\hline Test condition & Serum 1 & Serum 2 \\
\hline & $U / m l$ & $U / m l$ \\
SIRS activity in serum & & \\
$\quad$ Untreated serum & 130 & 100 \\
$\quad$ Antibody-absorbed serum & 12 & 15 \\
SIRS activity in supernatants & & \\
$\quad$ of lymphocytes treated & & \\
$\quad$ with serum & & 133 \\
$\quad$ Untreated serum & 180 & 100 \\
$\quad$ Antibody-absorbed serum & 180 &
\end{tabular}

* Serum from SRNS patients was added to pokeweed mitogen-stimulated splenocyte cultures that were assayed for PFC response $6 \mathrm{~d}$ later. Serum was tested with and without incubation with monoclonal antiSIRS antibody coupled to Sepharose.

${ }^{\ddagger}$ Lymphocytes $\left(3 \times 10^{6}\right.$ in $1.5 \mathrm{ml}$ medium) were incubated with $2 \%$ serum from SRNS patients for $24 \mathrm{~h}$, washed, and cultured for $24 \mathrm{~h}$ more. Culture supernatant was tested for SIRS activity on PFC responses. 
T lymphocyte subpopulation activated to produce SIRS by patient serum. Con A or IFN activate $\mathrm{OKT} 8^{+}$suppressor T cells to produce SIRS. To determine whether SRNS patient serum also activates lymphocytes expressing the T8 cell surface phenotype, PBMC were separated using monoclonal antibodies to T4 (helper/inducer) or T8 (suppressor/cytotoxic) antigen. In the experiment shown in Table VI, PBMC treated with patient serum were activated to produce SIRS. Treatment of PBMC with complement or anti-OKT4 antibody and complement did not abrogate SIRS production, but treatment with anti-OKT8 antibody and complement did prevent release of SIRS. Similarly, cells expressing the T4 phenotype (adherent to plates after treatment with anti OKT4 antibody) did not produce SIRS, but cells expressing the T8 phenotype produced SIRS when treated with patient serum. Results of these and two similar experiments show that serum from patients with SRNS activates an $\mathrm{OKT}^{+}$suppressor T lymphocyte to produce SIRS.

Effect of hydrocortisone on secretion of SIRS by PBMC from $S R N S$ patients. SIRS was previously shown to disappear rapidly from urine or serum of patients with SRNS after initiation of steroid therapy (1). To determine the effect of steroids on secretion of SIRS by patient lymphocytes, hydrocortisone was added to cultures of PBMC from four patients with SRNS at doses $\left(10^{-6}-10^{-7} \mathrm{M}\right)$ that approximate high therapeutic concentrations in patient plasma (13). Fig. 4 shows the results of a typical experiment. Supernatant from MCNS patient lymphocytes treated with hydrocortisone was as suppressive as supernatant of untreated lymphocytes. Further, a similar dose of hydrocortisone added to splenocyte cultures containing lymphocyte supernatant did not abolish suppression. Hydrocortisone alone did not alter control PFC responses (data not shown). These data show that hydrocortisone does not block secretion of SIRS by PBMC from SRNS patients and does not block suppression of PFC responses by SIRS secreted by patient lymphocytes.

Table VI. Phenotype of Lymphocytes Producing SIRS after Incubation with Serum from SRNS Patients*

\begin{tabular}{lcc}
\hline Cell treatment & Serum added & SIRS production \\
\hline & & $U / m l$ \\
Whole PBMC & - & $<5$ \\
Whole PBMC & + & 25 \\
C' $^{\prime}$ alone & + & 20 \\
Anti-OKT4 + C' & + & 67 \\
Anti-OKT8 + C' & + & $<5$ \\
T4 adherent & + & $<5$ \\
T8 adherent & + & $>100$ \\
T8 adherent & - & $<5$ \\
\end{tabular}

* PBMC from a healthy donor were cultured after treatment with monoclonal anti-OKT4 (helper/inducer) or anti-OKT8 (suppressor/ cytotoxic) antibody and complement, or complement alone. Alternatively, PBMC were positively selected by a plate separation technique allowing the antibody-treated cells to adhere to plates coated with goat anti-mouse IgG (see Methods for details). The resulting lymphocyte subpopulations and control PBMC were cultured with or without patient serum for $24 \mathrm{~h}$, washed, and cultured for $24 \mathrm{~h}$ more. Supernatants of these cultures were assayed for SIRS activity. Cells that were not adherent in panning behaved similarly to cells treated with antibody and $C^{\prime}$. Similar results were obtained in two other experiments utilizing different patient sera.

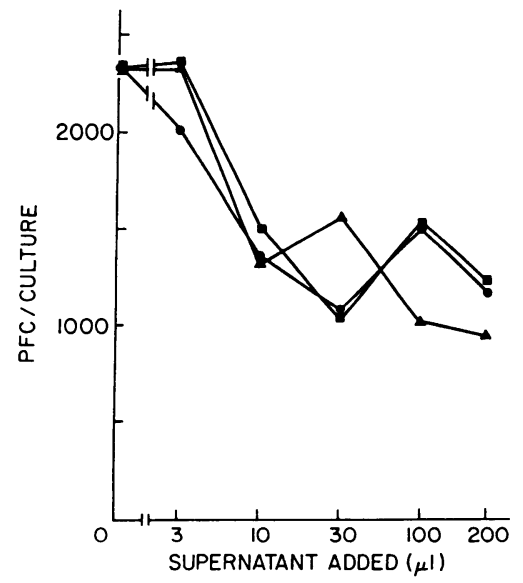

Figure 4. Effect of hydrocortisone on secretion of SIRS by PBMC from a patient with SRNS. PBMC from a patient with MCNS in relapse were cultured for $24 \mathrm{~h}$ in medium without (closed circle) or with (closed box) $3 \times 10^{-7} \mathrm{M}$ hydrocortisone. The culture supernatant was tested for suppressive activity in splenocyte cultures. In a third experimental grouping (closed triangle) 3

$\times 10^{-7} \mathrm{M}$ hydrocortisone was added directly to splenocyte cultures along with supernatant from a culture of untreated patient PMBC. Similar results were obtained in three other experiments.

Effect of hydrocortisone on suppression by agents that activate the SIRS pathway. These findings did not explain the relationship of treatment to the disappearance of SIRS activity observed in patients. To further investigate the role corticosteroids may play in regulating SIRS production, a series of experiments was undertaken examining the effect of hydrocortisone on in vitro SIRSmediated suppression. Agents such as anti-SIRS antibodies, which block SIRS activity, also block suppression by Con A or IFN $(3,6,9,14)$ and by suppressor cells activated by these agents (6). This suggests that suppression of PFC responses by Con A or IFN is mediated primarily through the SIRS pathway. Table VII shows a representative experiment examining the effect of hydrocortisone on suppression of PFC responses by Con A or IFN $\alpha$ A (leukocyte IFN A (IFLrA) provided by the Biopolymer Research and Immunotherapy Department of Hoffmann-La Roche Co., Nutley, NJ). Addition of $5 \times 10^{-7} \mathrm{M}$ hydrocortisone on day 0 of a 6 -d culture period significantly increased responses. Hydrocortisone added on day 1 had minimal inhibitory effect on suppression, and added on day 3 had no significant effect. Similar results were obtained in experiments with IFN $\gamma$ (immune

Table VII. Effect of Hydrocortisone on Suppression of PFC Responses by Con $A$ or IFNa $A^{*}$

\begin{tabular}{llc}
\hline Culture treatment & Hydrocortisone & PFC/culture \\
\hline None & - & 9,200 \\
None & Day 0 & 8,920 \\
Con A & - & 740 \\
Con A & Day 0 & 7,080 \\
Con A & Day 1 & 2,200 \\
Con A & Day 3 & 1,160 \\
IFN $\alpha$ A & - & 3,680 \\
IFN $\alpha$ A & Day 0 & 9,760 \\
IFN $\alpha$ A & Day 1 & 4,040 \\
IFN $\alpha$ A & Day 3 & 3,480
\end{tabular}

* Con A, $4 \mu \mathrm{g} / \mathrm{ml}$, or IFN $\alpha \mathrm{A}, 800 \mathrm{U} / \mathrm{ml}$, was added to pokeweed mitogen-stimulated splenocyte cultures at the initiation of a 6-d culture period. Hydrocortisone $\left(5 \times 10^{-7} \mathrm{M}\right)$ was added to the cultures on the day indicated. 
IFN). Agents that block activation of SIRS to SIRS $_{\text {ox }}$ or inactivate SIRS $_{\text {ox }}$, such as catalase and 2-mercaptoethanol (ME) $(2,15)$, inhibit suppression by Con A, IFN, or SIRS when added as late as day 3 or 4 of the culture period (6). In contrast, hydrocortisone is inhibitory only when added near the beginning of the culture period. Further, suppression by SIRS derived from normal lymphocytes activated by Con A or IFN, like that by SIRS derived from patient lymphocytes, was not inhibited by hydrocortisone (data not shown).

Effect of hydrocortisone on activation of suppressor cells. The finding that hydrocortisone inhibited suppression by agents that act through the SIRS pathway, but not suppression by SIRS itself, suggested that hydrocortisone inhibits suppression by preventing SIRS production by lymphocytes. Further, the failure of hydrocortisone to prevent secretion of SIRS by activated lymphocytes from patients suggested that hydrocortisone may block activation of suppressor cells. To investigate this possibility, normal splenocytes were incubated with Con $A, 30 \mu \mathrm{g} / \mathrm{ml}$, for $24 \mathrm{~h}$, washed, and added to pokeweed mitogen-stimulated cultures of splenocytes from the same donor. As is depicted in Fig. 5, $A$, Con A-treated cells suppressed PFC responses in a dosedependent manner. However, cells incubated with $5 \times 10^{-7} \mathrm{M}$ hydrocortisone as well as Con A had no suppressive activity; their effect was no different from that of cells incubated in medium alone for $24 \mathrm{~h}$. A similar effect was observed on SIRS production (Fig. 5, B). Normal PBMC or splenocytes incubated with Con $A$ for $24 \mathrm{~h}$ and then washed secreted SIRS into culture supernatant during the subsequent $24 \mathrm{~h}$. Similar to the findings with cultured PBMC from SRNS patients, addition of hydro-

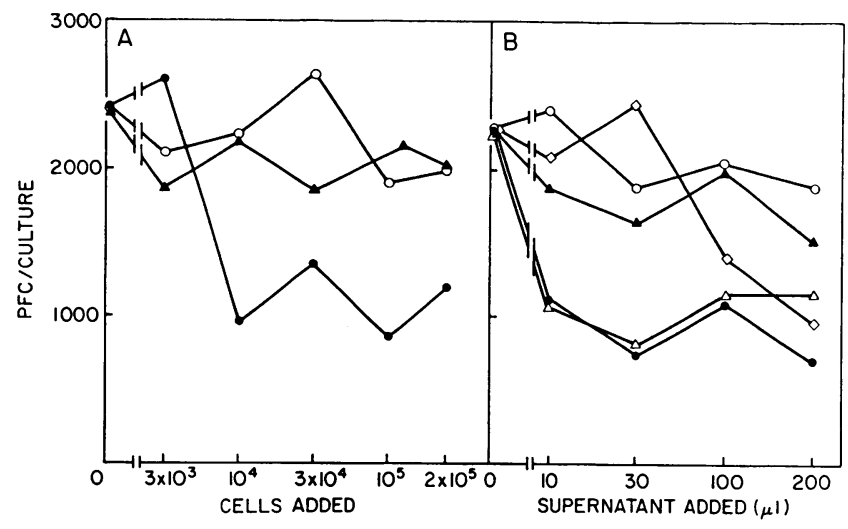

Figure 5. Effect of hydrocortisone on suppressor cell activation and SIRS production by lymphocytes treated with Con A. $(A)$ Suppressor cell activity was tested by incubation of normal spleen cells with plain medium (open circle), Con A, $30 \mathrm{mg} / \mathrm{ml}$ (closed circle), or Con A + 5 $\times 10^{-7} \mathrm{M}$ hydrocortisone (closed triangle) for $24 \mathrm{~h}$. The cells were then washed and added in graded amounts to syngeneic cultures of splenocytes stimulated with pokeweed mitogen. After $6 \mathrm{~d}$, PFC response of the splenocyte cultures was determined. $(B)$ SIRS production was assayed by incubating normal PBMC for $24 \mathrm{~h}$ with plain medium (open circle), or Con A, $30 \mathrm{mg} / \mathrm{ml}$ (closed circle, closed triangle, open triangle, open diamond). The cells were washed and cultured for 24 additional h, after which culture supernatant was tested for suppressive effect on PFC responses of splenocyte cultures. Hydrocortisone $\left(5 \times 10^{-7} \mathrm{M}\right)$ was added to PBMC cultures at the time of addition of Con A (closed triangle), $3 \mathrm{~h}$ later (open triangle), or after the Con A-treated cells were washed (open triangle). Similar results were obtained in two other experiments with Con $\mathrm{A}$ as the suppressor cellactivating agent and in several additional experiments utilizing IFN $\alpha \mathrm{A}$ or IFN $\gamma$ instead of Con A. cortisone to cultures of in vitro-activated suppressor cells during the period of SIRS collection did not block secretion of SIRS. However, addition of hydrocortisone at the time of addition of Con A completely blocked SIRS production. When hydrocortisone was added to cultures $3 \mathrm{~h}$ after addition of Con A, some SIRS was produced, but the quantity of SIRS released was decreased. Similar results were obtained in experiments evaluating the effect of hydrocortisone on activation of SIRS-producing lymphocytes by IFN $\alpha$ A or IFN $\gamma$. These data show that hydrocortisone blocks an early step in activation of suppressor lymphocytes to produce SIRS.

Effect of hydrocortisone on activation of SIRS production by SRNS patient serum. To determine whether hydrocortisone inhibits SRNS serum-induced activation of lymphocytes to produce SIRS, PBMC from normal donors were incubated with $2 \%$ patient serum, with or without $5 \times 10^{-7} \mathrm{M}$ hydrocortisone. Figure 6 shows the results of one of five such experiments. While serum caused significant SIRS activity to be released into culture supernatant fluids, lymphocytes incubated with serum and hydrocortisone produced no suppressive activity; supernatant of these cultures had a similar effect to that from cells incubated with medium alone. In other similar experiments, hydrocortisone consistently prevented production of SIRS by PBMC treated with patient serum.

\section{Discussion}

Nephrotic syndrome is often associated with clinical and experimental evidence of suppressed humoral and cellular immune responses. Reported findings include alteration in serum immunoglobulin isotype concentrations (16) and specific antibody titers (17), and suppression of delayed-type hypersensitivity to a variety of antigens (18). Increased suppressor cell activity (19) and suppressive activity of patient sera (20) have also been described. These abnormalities are usually reported to disappear in patients with SRNS who enter remission $(18,21)$. The cause of immune suppression is not known.

We previously reported that patients with SRNS excrete SIRS in their urine and may have SIRS present systemically, since SIRS activity can be detected in serum as well (1). This product of activated suppressor $T$ lymphocytes suppresses in vitro PFC responses of murine (11) and human (6) lymphocytes, division by neoplastic cells (2), and microtubule assembly (22). The ability of SIRS to inhibit in vivo generation of murine PFC responses and delayed-type hypersensitivity response to sheep erythrocytes (3) suggests that SIRS could mediate the suppressed immunity observed in patients with SRNS.

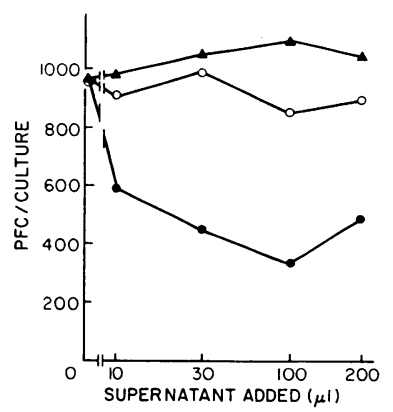

Figure 6. Inhibition by hydrocortisone of activation of normal PBMC to produce SIRS by SRNS patient serum. PBMC from a healthy donor were incubated for $24 \mathrm{~h}$ with control serum (open circle), serum from a patient with SRNS (closed circle), or patient serum $+5 \times 10^{-7} \mathrm{M}$ hydrocortisone (closed triangle), washed, and cultured for 24 additional hours before supernatants were harvested and assayed for suppressive activity on splenocyte PFC responses. Similar results were obtained in four other experiments. 
In the present paper, serum SIRS activity was found in the same spectrum of diseases that manifest urinary excretion of SIRS. Serum SIRS, like urine SIRS, disappeared with steroid therapy. This finding is consistent with the hypothesis that SIRS mediates immune suppression in these patients, since normalization of immune responses has been reported to occur with induction of remission in MCNS (18). Cultured PBMC from patients with SRNS secreted SIRS without requiring activation by exogenous agents. SIRS secreted by patient PBMC in vitro was antigenically and functionally similar to the factor previously identified in patient serum and urine. Further, all patients with urine or serum SIRS activity who were tested, and only these patients, had circulating lymphocytes that were activated to produce SIRS. These data suggest that activated suppressor cells may be the source of serum and urine SIRS activity. However, it is conceivable that other body tissues may also contribute to the systemic presence of SIRS.

Inhibition of responses by patient sera or by lymphocyte supernatant fluids was not total, with a plateau ranging between 50 and 80 percent suppression in different experiments. By contrast, suppression of murine plaque-forming cell responses by purified murine SIRS is more complete. Although the cause of this phenomenon is not known, experimental conditions that could affect the degree of suppression obtained include competing effects of other regulatory agents present in the sera or supernatants, the fact that responses are stimulated with mitogen in the human assay but with antigen in the murine assay, and differences in sensitivity to SIRS of human as opposed to murine splenocytes. The significance of the plateau of suppression seen in these experiments is uncertain.

The observation that SIRS activity disappears from serum after initiation of treatment also indicates that the previously reported disappearance of SIRS from patient urine may not result solely from changes in glomerular permeability. Treatment with corticosteroids appears to inhibit production of SIRS. Steroids do not prevent release of SIRS by activated lymphocytes, since secretion of SIRS by PBMC from patients with SRNS was not inhibited by hydrocortisone added to cultures. Instead, these drugs appear to prevent stimulation of suppressor cells to release SIRS. In patients with SRNS, steroid therapy may thus cause SIRS to disappear by blocking further activation of suppressor cells in vivo. The rapid disappearance of SIRS from body fluids, and the limited period of SIRS secretion by patient lymphocytes in vitro, suggest that the duration of SIRS production by activated suppressor cells in vivo is also brief. To produce the consistent levels of SIRS found in untreated patients with SRNS this would require that suppressor cells are continually being activated. $\mathrm{OKT}^{+}$lymphocytes from normal donors were activated to produce SIRS by incubation with serum from patients with SRNS, suggesting that a circulating factor may account for in vivo activation of suppressor cells in these patients.

The data obtained in screening nephrotic patients for SIRS production identify a group of patients characterized by remission of nephrotic symptoms after steroid therapy. All patients with SRNS produced SIRS by a mechanism that also appears to be steroid sensitive. In some cases, nephrosis and SIRS activity disappeared despite the persistence of glomerulonephritis, indicating that the mechanisms of albuminuria and SIRS production in SRNS are distinct from the glomerular inflammatory process; this concept is further supported by the presence in MCNS of albuminuria and SIRS production without renal inflammation. These observations suggest the existence of a com- mon pathway for albuminuria in SRNS, associated with SIRS production.

It has been proposed that MCNS represents a primary disorder of lymphocyte function (23). Although the findings reported here do not directly address the pathogenesis of SRNS, the strong association between SRNS and SIRS production raises the possibility that a common event or agent, through a mechanism blocked by steroids, could lead to both nephrosis and suppressor cell activation. Studies seeking to characterize the agent in SRNS serum that activates suppressor lymphocytes and determine its origins are in progress.

\section{Acknowledgments}

We appreciate the assistance of the Transplant Office of the Department of Surgery, Washington University School of Medicine, in obtaining human spleen. Carole Shieber and Paula Ryan provided valuable secretarial and administrative assistance. Dr. Schnaper is a recipient of Clinical Investigator Award KO8-AM-01317 from the National Institute of Arthritis, Diabetes, Digestive and Kidney Diseases. Dr. Aune is a recipient of Research Career Development Award KO4-CA01086 from the National Cancer Institute.

Supported in part by grant 1746 from the Council for Tobacco Research.

\section{References}

1. Schnaper, H. W., and T. M. Aune. 1985. Identification of the lymphokine soluble immune response suppressor in urine of nephrotic children. J. Clin. Invest. 76:341-349.

2. Aune, T. M., and C. W. Pierce. 1984. Mechanism of SIRS action at the cellular and biochemical level. Lymphokines. 9:257-277.

3. Schnaper, H. W., T. M. Aune, and C. W. Pierce. 1986. Suppression of immune responses to sheep erythrocytes by the lymphokine, soluble immune response suppressor (SIRS) in vivo. J. Immunol. 137:863-867.

4. Schnaper, H. W., and A. M. Robson. 1986. Nephrotic syndrome: Minimal change disease and related disorders. In Diseases of the Kidney, 4th Edition. R. W. Schreier and C. W. Gottschalk, editors. Little, Brown \& Co., Boston. In press.

5. Boyum, A. 1968. Isolation of mononuclear cells and granulocytes from human blood. Scand. J. Lab. Invest. 97 Suppl.(21):77-89.

6. Schnaper, H. W., C. W. Pierce, and T. M. Aune. 1984. Identifcation and initial characterization of concanavalin A- and interferoninduced human suppressor factors: evidence for a human equivalent of murine soluble immune response suppressor (SIRS). J. Immunol. 132: 2429-2435.

7. Gronowicz, E., A. Coutino, and F. Melchers. 1976. A plaque assay for all cells secreting Ig of a given type or class. Eur. J. Immunol. 6:588590 .

8. Schnaper, H. W., T. M. Aune, and C. W. Pierce. 1983. Suppressor $T$ cell activation by human leukocyte interferon. J. Immunol. 131:23012306.

9. Aune, T. M. 1985. ELISA for the detection of the lymphokine soluble immune response suppressor. J. Immunol. Methods. 84:33-44.

10. Lenarsky, C., S. C. Jordan, and S. Ladisch. 1982. Plasma inhibition of lymphocyte proliferation in nephrotic syndrome: correlation with lyperlipidemia. J. Clin. Immunol. 2:276-281.

11. Rich, R. R., and C. W. Pierce. 1974. Biological expression of lymphocyte activation. III. Suppression of plaque-forming cell responses in vitro by supernatant fluids from concanavalin A-activated spleen cell cultures. J. Immunol. 112:1360-1368.

12. Aune, T. M., and C. W. Pierce. 1982. Activation of a suppressor T cell pathway by interferon. Proc. Natl. Acad. Sci. USA. 79:3808-3812.

13. Schaffner, A. 1985. Therapeutic concentrations of glucocorticoids suppress the antimicrobial activity of human macrophages without im- 
pairing their responsiveness to gamma interferon. J. Clin. Invest. 76: 1755-1764.

14. Aune, T. M., and C. W. Pierce. 1983. Inhibition of interferon or soluble immune response suppressor (SIRS)-mediated suppression by levamisole. Int. J. Immunopharmacol. 5:91-98.

15. Aune, T. M., and C. W. Pierce. 1981. Conversion of soluble immune response suppressor to macrophage-derived suppressor factor by peroxide. Proc. Natl. Acad. Sci. USA. 78:5099-5103.

16. Giangiacomo, J., T. G. Cleary, B. R. Cole, P. Hoffsten, and A. M. Robson. 1975. Serum immunoglobulins in the nephrotic syndrome. A possible cause of minimal change nephrotic syndrome. N. Engl. J. Med. 293:8-12.

17. Lange, K., U. Ahmed, G. Seligson, and A. Grover. 1981. Depression of endostreptosin, streptolysin $\mathrm{O}$ and streptozyme antibodies in patients with idiopathic nephrosis with and without nephrotic syndrome. Clin. Nephrol. 15:279-285.

18. Fodor, P., M. T. Saitua, E. Rodriguez, B. Gonzales, and L. Schle- singer. 1982. T-cell dysfunction in minimal change nephrotic syndrome. Am. J. Dis. Child. 136:713-717.

19. Osakabe, K., and K. Matsumoto. 1981. Concanavalin A-induced suppressor cell activity in lipoid nephrosis. Scand. J. Immunol. 14:161166.

20. Moorthy, A. V., S. W. Zimmerman, and P. M. Burkholder. 1976. Inhibition of lymphocyte blastogenesis by plasma of patients with minimal change nephrotic syndrome. Lancet. i:1160-1162.

21. Matsumo, K., K. Osakabe, H. Katayama, and M. Hatano. 1982. Impaired cell-mediated immunity in lipoid nephrosis mediated by suppressor cells. Nephron. 32:270-272.

22. Irons; R. D., R. W. Pfeifer, T. M. Aune, and C. W. Pierce. 1984. Soluble immune response suppressor (SIRS) inhibits microtubule function in vivo and microtubule assembly in vitro. J. Immunol. 133:20322036.

23. Shalhoub, R. J. 1974. Pathogenesis of lipoid nephrosis: a disorder of $\mathrm{T}$ cell function. Lancet. ii:556-559. 